\title{
DISCRIMINATION ON DALIT IN KARNALI AND ITS IMPACT TO SUSTAINABLE DEVELOPMENT
}

Nepali, Govinda ${ }^{6}$

\begin{abstract}
There is constitutional provision to include the marginalized community i.e. Dalit in every step of development and structure of development but there are negligible representatives from Dalit community those are also targeted from elite Dalit. Inherited caste identity is an important determinant of life opportunities for Dalit communities where they have the historical skill and knowledge that could be advanced for the prosperity. This study asks why addressing development-based inequality and discrimination does not feature in inter-governmental commitments such as the sustainable development goals which clearly focuses on no one left behind in the development process. In order to trace out the political inequality of Dalit and to generalize the findings, both primary and secondary qualitative data have been interpreted and analyzed. The key informant interview method was employed to explore the experiences of Dalit on the current province government political inequality, identity debates, and representation. Furthermore, the review emphasizes the base of inequality in political representative and development process is the mindset of the political leader and more focus on the number of votes rather than the true implementation of the constitutional provision for inclusion. The history of Dalit culture and their deplorable situation in Karnali are suffering from the caste-based discrimination in the name of untouchability.
\end{abstract}

Keywords: Dalit, Inequality, Karnali district, Sustainable development.

\section{Background}

Dr. Haseena V, An Assistant Professor, Post Graduate Department of Economics M.E.S Kalladi College, Mannarkkad, Kerala, India Abstract The word "Dalit" comes from the Sanskrit root dal and means "broken, ground down, downtrodden, or oppressed." "Dalit" (Oppressed) is the name which the people belonging to those castes at the very bottom

\footnotetext{
${ }^{6}$ Mr. Nepali is PhD Scholars of Humanities and Social Science of Dean's Office, Kirtipur, TU. Email: govindanepali10@gmail.com
} 
of India's caste hierarchy have given themselves. It can be concluded that sustainable development and its impact for their life uplifting. (SDG), are one of the major institutional reforms for achieving Karnali's Dalit justice. Inequality development still persists in Dalits' socio- culture, educational, and economic status, despite a Dalit movement that has been struggling over the past 100 years to constitute their rights which needs to be addressed by the state (Ahuti, 2010). The sustainable development goals (SDGs) emphasize of equality of opportunity and reducing inequality of outcomes, the elimination of discrimination in law, policy and social practice, and socio-economic inclusion of all under the banner goal.' To leave nobody behind" "All” here means "irrespective of age, sex, disability, race, ethnicity, origin, religion or economic or other status" (SDG 10.2). In this context, this article explores how the Karnali's Dalit sustainable development and it impact of their people life. Karanli, is one of the high caste untouchability regions in the nation, which has direct impact on the Dalits' life and their development, because their people have traditional and Hinduism culture.

Dalits are 'outcastes' falling outside the traditional four-fold caste system consisting of the hereditary Brahmin, Kshatriya, Vaishya, and Shudra classes. In the history of Nepal, they are considered impure and polluting and are therefore physically and socially excluded and isolated from the rest of society. The deeply entrenched status inequality reinforced by caste hierarchy entails multiple forms of oppression. Dalits represent a community of 43 million in Nepal, constituting $21 \%$ of the total population. One out of every 10 Nepalese Dalit, yet due to their caste identity Dalits regularly face discrimination and violence, which prevent them from enjoying the basic human rights and dignity promised to all citizens of Karnali. Caste based social organization extends beyond Karnali (Ahuti, 2010). The indicators show that caste hierarchy and access to power influence access to the different forms of resources. Socio-cultural and sustainable development marginalization. In Karnali labor and landlessness are common issues.

In Nepal 43 million people are suffering from this "hidden apartheid" of segregation, exclusion, and discrimination. The official label for them has been scheduled sates, because if their caste is listed on the government schedule, caste members become eligible for a number of affirmative action benefits and protections. Dalit's have chosen the "Dalit" label for themselves for at least three important reasons (Olsen, 2011). This indicates that 
the condition of the Dalits has not been of their own making or choosing; it is something which has been inflicted upon them by others. There is an element of militancy built into the label; Dalits seek to overcome the injustices and indignities forced upon them so as to gain the equality and respect hitherto denied them. Share a common condition and should therefore unite in a common struggle for dignity, equality, justice and respect under a common name (Olsen, 2011). Nepalese caste system assigns individuals a certain hierarchical status according to Hindu beliefs. Traditionally, there are four principal castes (divided into many sub-categories) and one category of people who fall outside the caste system the Dalits. In Karnali Non-Dalit Communities are more powerful in all the sectors. The discrimination against the Dalits is especially significant because of the number of people affected.

Within the Dalit community in Karnali has three divisions Kami, Sarki, and Damai. Whose major works are blacksmith, leather workers, tailors, dancers, cobblers, agricultural sector, street sweepers, workers, and manual "scavengers". Three quarters of the Dalit workforce are in the agricultural sector of the economy. A majority of the Karnali's one and half million people who are bonded laborers are Dalits. Blacksmith, leather workers, clothing and dancing these jobs rarely provide enough income for Dalits to feed their families daily life and to send their children to school. As a result, many Dalits are impoverished, uneducated, and illiterate. The origins of the caste system the word Dalit literally translating to "oppressed" or "broken" is generally used to refer to people who were once known as "untouchables", those belonging to castes outside the fourfold Hindu Varna system (Ahuti,2010).

The caste system finds its origin in functional groupings, called varnas, which have their origins in the Aryan society of ancient southern and northern Karnali. The Creator's mouth became the Brahman priests, his two arms formed the Rajanya warriors and kings, his two thighs formed the Vaishya landowners and merchants, and from his feet were born the Shudra artisans and 2 servants. Later, there developed a so-called "fifth" varna: the untouchables. This caste system became fixed and hereditary with the emergence of Hinduism and its beliefs of pollution and rebirth. The Laws of Manu (Manusmitri), which dates roughly to the 3rd century A.D. and parts of which form the Sanskrit syllabus of graduation studies in Gujarat even today preach the sanctity of the Varna and uphold the 
principles of gradation and rank (Ahuti, 2010).

They refer to the impurity and servility of the outcastes, while affirming the dominance and total impunity of Brahmins. Those from the "lowest" castes are told that their place in the caste hierarchy is due to their sins in a past life. Vivid punishments of torture and death are assigned for crimes such as banning literacy or insulting a member of a dominant caste. Discrimination and untouchability have undermined the basic human rights of Dalit, inducing inequality in every sphere of their lives. Inequality induces multi-dimensional effects in Dalit's socio-economic, educational, and political condition. Unequal status underpins unequal distribution of power resources (Olsen, 2011). Similar to in the economic sphere, the status inequality effects on education are a literacy rate for Dalit of $52.4 \%$ compared to $81.9 \%$ for the higher caste Brahmin (Sharma, 2014). Status inequality also has detrimental effects on the political dimension.

Dalits are neither sufficiently represented in the political party structure nor in the governance mechanism. Dalit are most similar to other subordinated groups, particularly those excluded from any meaningful social, economic, or political participation, those with no voice in society, and those whose subordination is as a consequence of the hegemony of the ruling classes. Dalit comprise 13 percent of the Nepalese population, were previously known as an untouchable group, and include 26 separate sub-caste groups. Dalit are divided mainly into the two categories of Hill Dalit and Terai Dalit. According to the National Dalit Commission (2016), among 26 different caste groups of Dalits seven are from Hill and 19 from Terai. Dalit used to be known as the 'Sudra', 'Untouchable', 'Kujat', Pauni', or 'Atisudra'. Derogative terms used to dominate them in society (Ahuti, 2010; Muthaiah, 2004).

The Dalit word emerged when renowned Dalit leader Dr Ambedkar used it to address all the caste groups who were primarily oppressed through the untouchability practices of the Varna system in Hindu society. The use of the word 'Dalit' was initiated during the Dalit struggle that emerged in 1927 A.D. in India. The term is derived from the Hebrew root 'Dal' meaning 'broken' or 'crushed'. In Sanskrit it means 'downtrodden', 'oppressed', or 'exploited' (Muthaiah, 2004). It is considered that Dalit are broken from the society and living outside of it (Muthaiah, 2004). When the word Dalit is spoken by a non-Dalit it might have the character of a derogatory remark. According to the Nepali 
vocabulary, Dalit means 'oppressed' or 'suppressed', although it refers not only to the Dalit of Nepal and India but also to all disadvantaged groups oppressed by caste-based untouchability practices (Ahuti, 2010). 'Yet for Dalit themselves the term has become a place of resistance and a reason for struggle' (Zene, 2010).

Dalit identity is contested within the group, mostly by the younger generation who are reluctant to consider 'Dalit' as their identity because of its negative signifiers of being lower caste and untouchable; a larger section of Dalit social and political leaders affirms the significance of a common identity for resistance against all forms of caste-based discrimination (Ahuti, 2010). Dalit politics is also to annihilate all forms of derogatory perception and to constitute their dignity through group politics in the society. In this sense, group differentiated politics is a strategy for the Dalit struggle since it is necessary, as argued by Kymlicka (1995), for undermining oppression and promoting social justice. In this context, in order to retain Dalit rights, as argued by Fraser (2003), both redistribution of resources and power and the recognition of the Dalit group are significant for attaining social justice for Dalit.

\section{Objectives}

To explore out the status of Karnali Dalits

To find out the representation of Karnali Dalits representation in Nepalese governance system.

\section{Methodology}

Methodologically, The research question, in-depth interview, and logical frame works had been conducted with Karnali's Dalit, non-Dalit leader and civil society members. From all leader and civil society together 27 interviews were conducted for this study. Among the interviewee sixteen were female and eleven were male of Karnali Dalit. The respondents were asked questions related to the sustainable development and its impact on Karnali's people life and representation of Dalit, challenges for directly involved on development participation, which fit the scope of this study. The interviews were conducted in the respondents' preferred "Khas" language and were later transcribed into English. The participants for interview were selected based on the basis of quota sampling selection 
method in order to explore the specific development representation context of the Karnali's Dalit. The secondary data were collected from different academic books, journal articles, literatures, research reports, magazine, published in different online pages.

\section{Results and discussion}

Hundred years of Nepalese Dalit history shows that despite frequent development transition in Karnali, the data shows Dalit have never been in decision level to just make corium for meeting and make sign only. The Karnali's Dalit people are still politically excluded and oppressed in society. The structural injustice induced by caste hierarchy persists and causes multidimensional effects on Dalit, and it is a deep-rooted reason for Dalit exclusion and powerlessness. Ineffective act of policy and a lack of government mechanisms to enforce those policies are the prime impediments, as well as the political parties and rulers not being sensitive to Dalit concerns. In addition to policy and implementation gaps, there are several internal and external challenges for Karnali Dalit. The following section will highlight the major results and discussion of this research.

Government of Nepal (GoN) Employees Province No: 6, Karnali province

Low rank job (Non-posted) $1 \%$

Middle rank Job (Khadihar, Subba) 0012\%

Upper rank Job (Officer and Above) $000001 \%$

Decision level employees $0 \%$

$0.1 \%$ people changing their family life

Non-Government Organization (NGO) Employees

Low rank job (Non-posted) $02.03 \%$

Middle rank job (Khadihar, Subba ) $0.13 \%$

Upper rank job (Officer and Above) $001 \%$

$0.3 \%$ people are changing their family life

\section{Indigenous knowledge:}


Damai : $32 \%$ are working with Indigenous knowledge

Kami: $33 \%$ are working with Indigenous knowledge

Sarki: $11 \%$ are working with Indigenous knowledge

Due to the Kami 67\%, Dami $68 \%$ and Sarki $89 \%$ are working on Skill labor and house building work

(Field survey 2018 Jan to Aug)

Unfair and Inequality development and it impact on Sustainable development

Inequality development refers to the unequal influence over decisions made by political bodies and the unequal outcomes of these decisions. This inequality is a subtype of power inequality; visible within the political processes of all kinds of political structures, it is analogously a dimension of democracy and of stratification (Dubrow, 2015). Political inequality means structural differences in the distribution of political resources. Political resources are anything that can be used to influence political decisions, such as social and psychological factors, an authority position, a network connection or action, or political participation (Dahl, 1996). The case study of the Dalit in Karnali. The power relations exclude a community from such political opportunity and resources. Political representation has been developed in the context of group representation (Pitkin, 1967). It is manifested in the composition of political institutions, as visible in the presence in numbers. It demands embracing groups of all backgrounds and characteristics so that political settings can address all citizens' voices and reflect society as a whole (NNDSWO, 2012). In the context of Dalit, the first condition for meaningful representation is representation in political institutions in adequate numbers, either proportional or a form of constructive overrepresentation. As Dalit in Karnali have been extremely excluded and are relatively unfamiliar with formal procedures and informal norms of political institutions, it perhaps makes more than proportional representation (PR) appropriate (Khanal et al., 2012). In the context of the Dalit political process, it is equally important to look at the trend of the institutionalization of Dalit politics.

As argued by Gorringe (2005), institutionalization refers to the process whereby social movements enter into the political system, adapt to processes of political representation, 
and formalize organizational structures. At the same time, it may be considered an instrumental means for gaining power for private benefits (Scaff, 1975). Political participation in general terms entails the involvement of people in the political process, association in political parties, engaging in actions, voting, candidacy for election, asking for votes, election campaigning, and policy formation. The Dalit political movement is as long as the history of the struggle of Nepalese democracy which was started formally in 1947; nevertheless, the movement has not yet gained enough momentum to bring remarkable change in political representation (Kisan, 2005; Shrestha, 2013). A group of Dalit youths led by Bhagat Sarbajit Bishwakarma initiated the liberation struggle 'Vishwa Sarbajan Sangh' in Baglung in 1947-1948 as a separate organization particularly to fight caste discrimination. But, despite having this long history, there is not yet even a single Dalit led political party in Nepal.

The political change in 2006, adopting an inclusive electoral policy, brought substantial change to Dalit representation in the national legislatures (Kisan, 2011). In the second election in 2013, the number of Dalit decreased by $1 \%$ and only two members were directly elected. The mixed method election combination of First Past the Post (FPTP) and PR helped to bring positive results, although it was not sufficient on the basis of PR. According to by Min BK, leader of the Nepali Congress, the key reasons for the low probability of Dalit success in direct elections are that. Inclusion statistics for different political parties show that Dalit participation in their central committees is lower than in local committees (Bhattachan et al., 2008). Political inequality interrelates with the socioeconomic, educational status of Dalit which is in general in a fragile condition.

Nepalese political parties are principally founded either in Communist or in social democratic ideology. While the Dalit movement has articulated the social and political aspirations of the oppressed community, a Marxist understanding and placing the Dalit movement within a larger national and worldwide struggle for emancipation complements this social and political approach. Political parties were bound by this law to nominate a proportional ratio of the caste/ethnic and gender groups. As we can observe, the results of the 2008 and 2013 constituent assembly elections clearly show the inclusive results in terms of ethnic, disadvantaged, and women's representation. The inclusive representation was only possible due to a mixed electoral policy. 
The better opportunities for Dalit after 2006 were extended to more groups inside the community (IDSN, 2013). Nevertheless, exclusion within the Dalit community has continued. In the 2008 CA election, a total of 50 Dalit represented through the mixed method system, of which only a few were Tarai Dalit. Sewal Ram, one of the active Terai Dalit political leaders, described the miserable socio- political situation of Terai Dalit when interviewed for this research: In previous general elections, Dalit were nominated in areas where there was no party hold. In 2008, Dalit were nominated for the party hold areas with full party support for the election campaign and incumbent expenditures - a historic achievement (Kisan, 2011).

The following section will highlight the major results and discussion of this research.

Political Status of Dalit In Karnali:

Very less $1 \%$ Dalit people are involved in local level

Very less 001\% Dalit people are involved in district level

Very less $0001 \%$ Dalit people are involved in province level

(Field survey, 2074/6/ 15 to 2075 / 1 / 30)

This flaw means that marginalized groups like Dalit have a lower chance of being nominated for smaller parties. There are few defects on the utilization of the PR quota by political parties. Nonetheless, the evidence shows that political parties also nominate their relatives, business contacts, and elites instead of marginalized groups (Ghimire, 2015). This pattern is further obstructing the chance of Dalit and other marginalized groups to increase their representation. In addition to this, there is criticism that candidates selected under the SD system do not represent the particular electoral constituencies as they are centrally nominated by the political parties. Non-representation of a specific constituency fosters an undemocratic process and outcome because SD impedes the local accountability of politicians.

This impedes the meaningful participation of Dalit both in political party institutions and in legislature. For example, CA members nominated by some political parties were more responsible to their party agendas rather than to Dalit in general (Ahuti, 2010). Despite 
this criticism, in Nepal the PR quota system is one of the main reasons for increased Dalit representation in national legislature. But firstly, they are not sufficiently represented and secondly there is the question of meaningful representation. One of the key reasons for the low political inclusion of Dalit is their lower socio-economic status. The society is also not ready to accept Dalit leadership due to the huge- monic power relation. This has hardly provided Dalit's with the political and institutional space to set the agenda and represent their community.

\section{Conclusion}

Karnali Dalit holds $0.23 \%$ of the total Nepalese population, but their control over resources of the country is negligible i.e. $0.89 \%$. Close to half of the Dalit population lives under the poverty line in Karnali Region, and even more (59\%) are illiterate. Among the Dalits, most of those engaged in agriculture but they do not have their land ownership or nearly landless agricultural laborers. The average household income for Dalits was Rs. 15000 in 2075 , just $78 \%$ of the national average. According to the recent data the representation of Karnali Dalit in different government structure and policy making position, there is almost zero which is because of the capture of elite Dalit in the name of education, accessibility to the resources and politics. Not only those, the Karnali Dalit have no connection with the national networks, forum to raise their voice and recognized their originality.

This is the good opportunity for the Dalit community in the initial stage of implementing the national federal system. Dalit community should be aware about the constitutional provision and claim the rights of meaningful engagement in decision making process at all level i.e. local, province and federal. The Dalit community needs to be united and raise their voices to claim their rights ensuring their representation in politics, management and civil society forum which is proven and owned by constitution, international principles.

Karnali's history shows that despite frequent sustainable development transition to a democratic inclusive system, marginalized groups like Dalit are still politically excluded and oppressed in society. In this context, revaluation of Dalit group identity and redistribution of power and resources are crucial to rectify the injustice faced by Dalit in Karnali. The goal of Dalit power politics is to achieve equality and justice similar to other dominant groups in society. Dalit from Karnali are to be united and make their community 
aware on the rights of the community. As seen from the past, educated Dalit already left the community in the name of further education, jobs and other success in life. They are now deemed to exploit from elite Dalit at national scenario as well. Contextualizing the present constitutional provision, Dalit from Karnali need to forcefully claim their inclusive participation in decision making process, politics and another administrative domain.

\section{References}

Ahuti, (2010). Varna System and Class Struggle in Nepal. Kathmandu: Samata Foundation. Bhattachan, K., Sunar T., \& Bhattachan, Y. (2008). Caste Based Discriminations in Nepal. New Delhi: IIDS.

Dahal, R.A. (1996). Equality versus inequality. Political Science \& Politics 29(4): 639648.

Dubrow, J.K. (2015). Political inequality is international, interdisciplinary, and intersectional. Sociology Com- pass 9(6): 477-486.

Fraser, N. (2003). Rethinking recognition: Overcoming displacement and reification in cultural politics. In: Hobson B (ed.) Recognition Struggles and Social Movements: Contested Identities, Agency and Power. Cambridge: Cambridge University Press, pp. 21-32.

Ghimire, N.P. (2015). Threshold essential to check maladies of proportional election. The Rising Nepal: THT. Available at: http://therisingnepal.org.np/news/4935.

Gorringe, H. (2005). Untouchable Citizens: Dalit Movements and Democratization in Tamil Nadu. Vol. 4. New Delhi: SAGE Publications.

IDSN, (2013). Nepal: Dalit Political Participation and the 2013 Election. Available at: http://idsn.org/wp-con tent/uploads/user_folder.

Khanal K, Pyakurel., U \& Gelpke F, (2012). Dalit Representation in National Politics in Nepal. Lalitpur: NNDSWO.

Kisan, Y.B. (2005). The Nepali Social Dalit Movement. Kathmandu: Legal Rights 
Protection Center.

Kisan, Y.B. (2011). Ethnic identity-based federalization and Dalit. Paper presented at the Federalism Symposium Kathmandu: Nepal, 22-25 April 2011.

Kymlicka, W. (1995). Introduction. In: Kymlick W (ed.) The Rights of Minority Culture. Cambridge: Cambridge University Press.

Muthaiah, P. (2004). Politics of Dalit identity. The Journal of Political Science 65(3): 385-402.

National Dalit Commission (NDC) (2016). Caste Category of Dalit 2016. Available at: http://ndc.gov.np/np/ cms/4.

Olsen, G.M. (2011). Power \& Inequality: A Comparative Introduction. Toronto: Oxford University Press.

Pitkin, H.F. (1967). The Concept of Representation. Los Angeles, CA: University of Los Angeles Press.

Scaff, L. (1975). The concept of political participation. Political Research Quarterly 28(3): 47-462.

Sharma, P. (2014). Some Aspects of Nepal's Social Demography. Kathmandu: Himal Books.

Shrestha, T. (2013). Dalit Baodhikka Bisesata (Characteristics of Dalit Intellectuals). Retrieved on Nov 18, 2013 from http://www.ekantipur.com/kantipur/news/newsdetail.php?news_id=309035.

Zene, C. (2010). Self-consciousness of the Dalits as "Subalterns": Reflections on Gramsci in South Asia. University of London. Retrieved from http://eprints. soas.ac.uk/11711/1/ZENE_C._Self-Consciousness_of_the_Dalits_\%28RM_Jan_2010\%29.pdf. 